\title{
Transitional Cell Carcinoma of the Bladder Manifestating as Malignant Lymphoma with Generalized Lymphadenopathy
}

\author{
Venkat Pavan Kancharla ${ }^{a}$ Frederick A. Gulmi ${ }^{b}$ Aref Agheli ${ }^{a}$ \\ Michael Degen $^{b}$ Arash Goharic $^{\mathrm{c}}$ Ming Jiang $^{\mathrm{d}}$ J.C. Wang ${ }^{\mathrm{a}}$ \\ ${ }^{a}$ Division of Hematology/Oncology, Departments of bUrology, ${ }^{\text {cRadiology, and }}$ \\ dPathology, Brookdale University Hospital Medical Center, Brooklyn, N.Y., USA
}

\section{Key Words}

Transitional cell bladder cancer - Malignant lymphoma - Generalized lymphadenopathy . Metastasis

\begin{abstract}
Bladder cancer usually spreads via the lymphatic and hematogenous routes, the most common sites of metastases of urinary bladder cancers being the regional lymph nodes, liver, lung, bone, peritoneum, pleura, kidney, adrenal gland and intestines. Generalized lymph node metastasis of transitional cell cancer of the bladder is extremely rare. According to our literature search, there has been no case report of transitional cell cancer of the bladder that manifests as an extensive large lymph node metastasis involving the intraparotid, supraclavicular thoracic inlet, axillary and regional abdominal and pelvic lymph nodes without bone or visceral organs involved. Such a presentation could be mistaken as malignant lymphoma and the importance of a biopsy of the lymph nodes is emphasized. The clinical course of rapid progression of the disease and the presence of wild-type p53 with rapid response to chemotherapy and a short remission may represent a unique case, which is discussed here.
\end{abstract}

\section{Introduction}

Urinary bladder cancer (UBC) is the 4th and 9th most frequent cancer diagnosed in men and women, respectively, in the United States. It was estimated that 70,980 new cases of UBC and 14,330 related deaths would occur in the United States in 2009 [1].

The presence of microscopic or macroscopic metastases at diagnosis is responsible for the incurability of invasive urothelial cancer [2]. Lymph node metastases are found in 20 
to $25 \%$ of patients with UBC, mainly in the external and internal iliac and the obturator sites as the primary lymphatic drainage of the bladder and the common iliac sites as the secondary drainage. These are the most common lymph nodes involved with metastatic UBC [12]. However, generalized lymph node metastasis, with involvement of the lymph nodes above the diaphragm, mimicking an aggressive lymphoma in UBC, is extremely rare. To the best of our knowledge, this is the first case of advanced urinary bladder carcinoma presenting as a lymphoma-like picture with extensive lymph nodes involvement and without any bony or visceral metastasis.

\section{Case Report}

In April 2008, a 58-year-old Caucasian male with a past medical history of hypertension was admitted to our institute with a one-month history of hematuria. His social history was relevant for having smoked one pack per day for 20 years, which he stopped about 15 years ago, and consuming a moderate amount of alcohol. He had hadnumerous tattoos on his body when he was young. Family history included his mother having had a urinary bladder carcinoma at age 70 . He initially underwent cystoscopy, during which he was noted to have a bladder mass. Therefore, transurethral resection of bladder tumor was performed. The pathologic examination of the mass revealed high-grade (3/3) transitional cell carcinoma (TCC) with invasion to the lamina propria, but not to the muscularis propria. He was then treated with intramucosal Bacillus Calmette-Guérin therapy. A follow-up cystoscopy in August 2009 revealed evidence of recurrence. Therefore, imaging studies were obtained. A computed tomography scan of the abdomen and pelvis showed an abnormally thick and nodular bladder wall with diffuse infiltration of the prevesical fat, consistent with recurrent bladder tumor with multiple enlarged retroperitoneal, bilateral common iliac, external iliac obturator, and femoral lymph nodes which were not noted in the prior studies (fig. 1). Biopsies of the bladder mass and pelvic lymph nodes were obtained. Pathologic examination of the samples confirmed recurrent urothelial carcinoma, which was further supported by immunohistochemical staining (fig. 2). During the one-month interval in which the patient was being prepared for further treatment he was found to have generalized multiple lymphadenopathy in cervical and axillary regions bilaterally, which were more prominent on the left side (fig. 3). In addition, he had multiple enlarged left supraclavicular and left axillary lymph nodes. A PET scan was obtained, which demonstrated focal hypermetabolic uptake in multiple lymph nodes, including the intraparotid, supraclavicular, left thoracic inlet, left axillary, right retrocrural, peripancreatic, aortocaval, left paraaortic, and bilateral external iliac chain, which was suggestive of malignant lymphoma. There was no other visceral or bony metastatic disease. HIV and hepatitis serologic testing was negative. Biopsy of the cervical lymph nodes was done to rule out lymphoma and the pathology was consistent with metastatic urothelial carcinoma with negative marker for CD45 (fig. 4). The sample was examined for the $\mathrm{p} 53$ gene mutation, which was negative. In a short period of time the patient developed severe jaundice with a total bilirubin level of $26 \mathrm{ng} / \mathrm{ml}$. An MRI cholangiogram was done, which showed obstruction of the common bile duct most likely secondary to impingement by lymph node metastasis. In view of the rapid progression of the disease, combination chemotherapy with $100 \mathrm{mg} / \mathrm{m}^{2}$ cisplatin on day 1 , and $1,000 \mathrm{mg} / \mathrm{m}^{2}$ gemcitabine on days 1 and 8 , every 21 days, with a $50 \%$ dose reduction of gemcitabine because of high serum bilirubin levels, was started. After one cycle of chemotherapy, the jaundice had decreased considerably. Moreover, the cervical lymphadenopathy was barely palpable. There was also a significant decrease in the perivesical and pelvic lymphadenopathy. After the 2nd cycle of chemotherapy on regular follow up we noted that the patient had acute renal failure with a significantly decreased kidney function. Imaging studies did not show any external obstruction, so a cystoscopy was performed and an apparent carcinoma of the urinary bladder was observed. Bilateral urethral stents were placed, which improved the kidney function. Repeat imaging studies showed bilateral pulmonary lesions suspicious of metastasis but the pelvic and cervical lymphadenopathy had markedly decreased. The chemotherapy was changed to carboplatin plus paclitaxel but the patient developed diplopia. An MRI of the head was done which showed metastasis to the putamen, for which the patient received radiation therapy. The patient expired suddenly after he had collapsed at home. Autopsy was not obtained. 


\begin{tabular}{|c|c|c|c|}
\hline $\begin{array}{l}\text { Cose Reports in } \\
\text { una.ayly }\end{array}$ & $\begin{array}{l}\text { Case Rep Oncol 2010;3:125-130 } \\
\text { D0I: } 10.1159 / 000312424\end{array}$ & Published online: April 30, 2010 & $\begin{array}{l}\text { @ } 2010 \text { S. Karger AG, Basel } \\
\text { ISSN } 1662-6575 \\
\text { www.karger.com/cro }\end{array}$ \\
\hline
\end{tabular}

\section{Discussion}

The lymph node drainage from the superior part of the bladder passes to the external iliac lymph nodes, and those from the inferior part of the bladder pass to the internal iliac nodes. Some lymphatic vessels from the neck region of the bladder drain into the sacral or common iliac lymph nodes. In a report of 107 patients, the most common site of metastasis of UBC was the regional lymph nodes (78\%). Other common sites include the liver (38\%), lung (36\%), bone (27\%), adrenal gland (21\%), and intestine (13\%) [2]. Many unusual sites of metastatic UBC have also been reported. In the same series, Babaian et al. reported metastases in the heart, brain, kidney, spleen, pancreas, meninges, uterus, ovary, prostate, and testes in 1 to $8 \%$ of their patients [2]. The pattern of recurrence and metastases are not dependent on the features of the primary tumor [3]. There is no difference in the frequency and location of metastasis between TCC and squamous cell carcinoma of the bladder. The frequency of metastases increases with local tumor extension [4]. Metastases of urothelial bladder cancer to the head and neck area and cervical or axillary lymph node sites occur in a very low rate, according to a retrospective autopsy study [5]. Hessan et al. retrospectively reviewed 845 cases of urogenital tract tumors for metastases to the head and neck area lymph nodes. Of 207 patients with metastasis, only 3 cases had metastasis with UBC in origin [6]. There are no reported cases of UBC with extensive lymph node involvement without any bone or other visceral organs involved, in which cases may be mistaken for malignant lymphoma. The present case demonstrates that TCC can rarely manifest as a lymphoma-like picture, and emphasizes again that a biopsy of lymph nodes is necessary to confirm the histology diagnosis.

Systemic cisplatin-based chemotherapy is the standard approach for patients with inoperable, locally advanced or metastatic disease, with average response rates of approximately $50-60 \%$ [7]. Advanced TCC of bladder is moderately sensitive to cisplatinbased combination chemotherapy; a variety of drugs are shown to have activity. Combination chemotherapy in patients with metastatic disease achieves $0-35 \%$ complete response and an overall response rate of $12-73 \%$ [8]. Gemcitabine plus cisplatin is equally effective and less toxic than methotrexate, vinblastin, Adriamycin, and cisplatin (MVAC). For patients not suitable for cisplatin-containing regimens, carboplatin-based regimens or gemcitabine plus taxanes can be substituted [9].

Mutation of p53, a well-characterized tumor suppressor gene which is located on chromosome 17p13.1, is one of the most common genetic events in urothelial tumors. There appears to be an association between $\mathrm{p} 53$ expression of the primary tumor and the stage and grade of the tumor, and lymph node metastasis. p53-stain negative tumors are more likely to be organ-confined and of lower grade [10], while overexpression of mutant p53 protein is generally associated with poorly differentiated invasive bladder tumors [11]. The presence of wild type p53 and the rapid progression of disease in this patient remain unexplained. A lymphoma-like presentation may suggest rapid progression of this type of aggressive UBC. The rapid response to chemotherapy may be related to the wild type of p53. A short duration of response to cisplatin chemotherapy and rapid progression of the presented case may be related to this unique type of carcinoma of the urinary bladder presenting as a malignant lymphoma-like picture. 


\begin{tabular}{c|l|l|l}
$\begin{array}{c}\text { Cose Reports in } \\
\text { Onculagy }\end{array}$ & $\begin{array}{l}\text { Case Rep Oncol 2010;3:125-130 } \\
\text { D0I: 10.1159/000312424 }\end{array}$ & Published online: April 30, 2010 & $\begin{array}{l}\text { O 2010 S. Karger AG, Basel } \\
\text { ISSN 1662-6575 } \\
\text { www.karger.com/cro }\end{array}$ \\
\hline
\end{tabular}

Fig. 1. Contrast-enhanced computed tomography scan demonstrating thickening of left lateral bladder wall, enlarged pelvic lymph nodes and perivesical lymph nodes before chemotherapy.
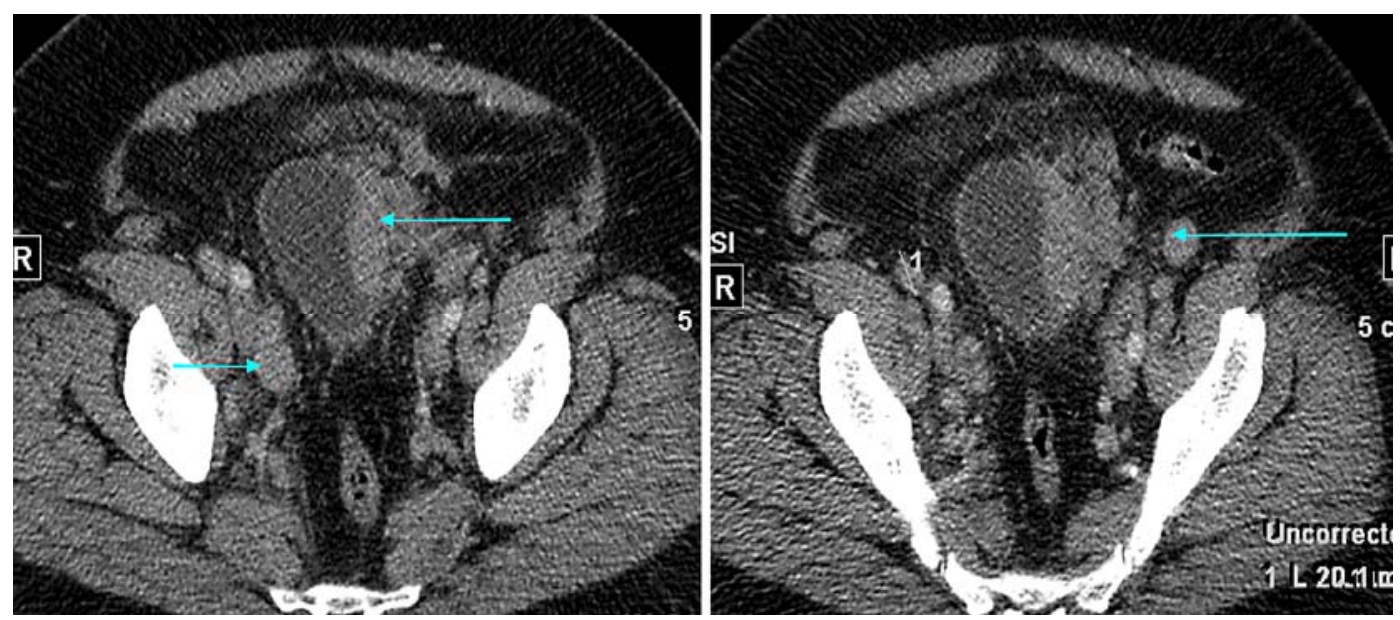

Fig. 2. Core biopsy of left pelvic lymph node demonstrating lymphoid tissue with infiltration of malignant cells, consistent with metastatic urothelial carcinoma on immunohistochemical tumor analysis.
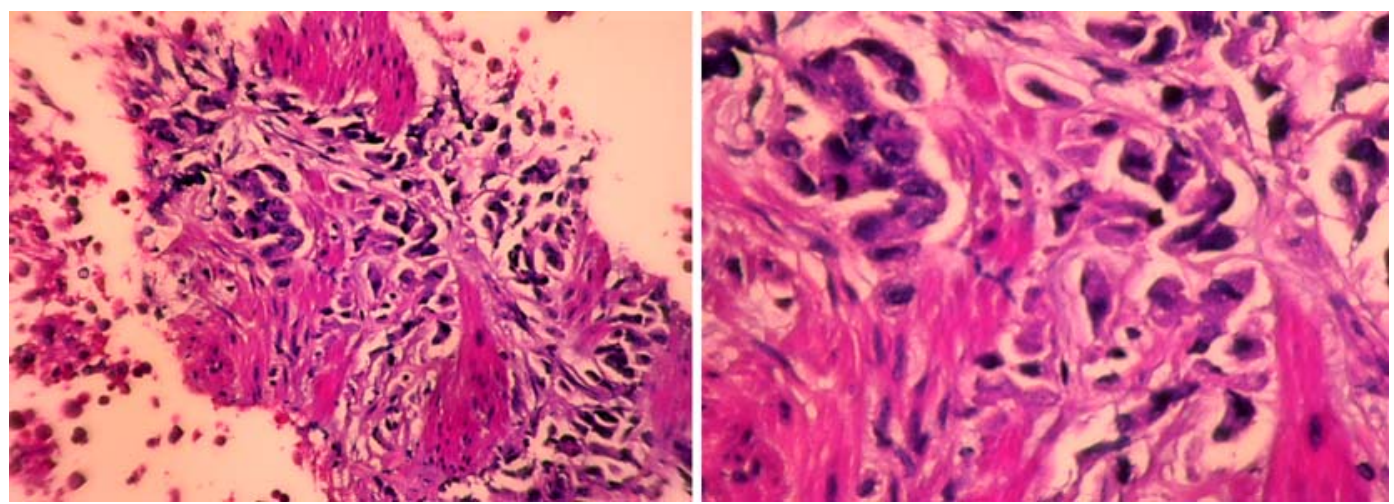

Fig. 3. Contrast-enhanced computed tomography scan demonstrating bilateral cervical lymph nodes before chemotherapy; the left side is more enlarged than the right.
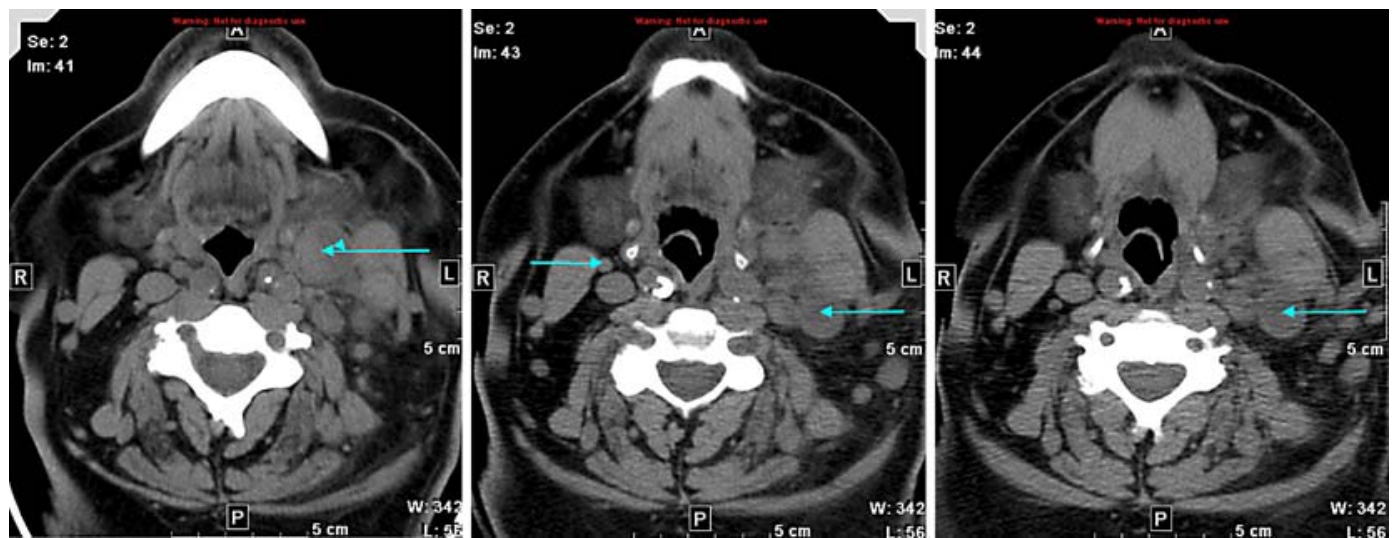


\begin{tabular}{c|l|l|l}
$\begin{array}{c}\text { Case Reports in } \\
\text { Oncolady }\end{array}$ & $\begin{array}{l}\text { Case Rep Oncol 2010;3:125-130 } \\
\text { D0I: 10.1159/000312424 }\end{array}$ & Published online: April 30, 2010 & $\begin{array}{l}\text { O 2010 S. Karger AG, Basel } \\
\text { ISSN 1662-6575 } \\
\text { www.karger.com/cro }\end{array}$ \\
\hline
\end{tabular}

Fig. 4. Core biopsy of left cervical lymph node demonstrating fibrous tissue with infiltration of malignant cells, consistent with urothelial carcinoma confirmed by immunohistochemical tumor analysis.

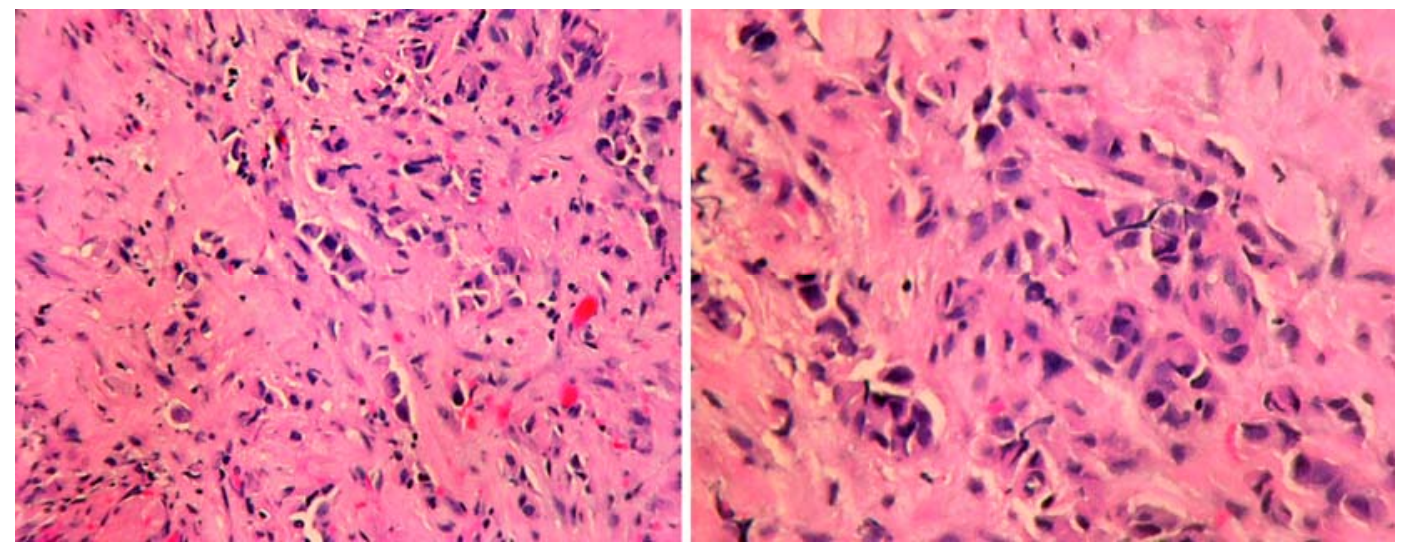




\begin{tabular}{|c|c|c|c|}
\hline $\begin{array}{l}\text { Case Reports in } \\
\text { Onatis }\end{array}$ & $\begin{array}{l}\text { Case Rep Oncol 2010;3:125-130 } \\
\text { D0I: 10.1159/000312424 }\end{array}$ & Published online: April 30, 2010 & $\begin{array}{l}\text { (c) } 2010 \text { S. Karger AG, Basel } \\
\text { ISSN } 1662-6575 \\
\text { www.karger.com/cro }\end{array}$ \\
\hline
\end{tabular}

\section{References}

1 Horner MJ, Ries LAG, Krapcho M, Neyman N, Aminou R, Howlader N, Altekruse SF, Feuer EJ, Huang L, Mariotto A, Miller BA, Lewis DR, Eisner MP, Stinchcomb DG, Edwards BK (eds): SEER Cancer Statistics Review, 1975-2006. National Cancer Institute. Bethesda, MD, (http://seer.cancer.gov/csr/1975_2006/) based on November 2008 SEER data submission, posted to the SEER web site, 2009.

2 Babaian RJ, Johnson DE, Llamas L, Ayala AG: Metastases from transitional cell carcinoma of urinary bladder. Urology 1980;16:142-144.

3 Sengelov L, Kamby C, von der Masse H: Pattern of metastases in relation to characteristics of primary tumor and treatment in patients with disseminated urothelial carcinoma. J Urol 1996;155:111-114.

4 Ferlito A, Shaha AR, Buckley JG, Caruso G, Rinaldo A: Metastatic cervical lymph nodes from urogenital tract carcinoma: a diagnostic and therapeutic challenge. Acta Otolaryngol 2001;121:556-564.

5 Wallmeroth A, Wagner U, Moch H, Gasser TC, Sauter G, Mihatsch MJ: Patterns of metastasis in muscle invasive bladder cancer (pT2-4): an autopsy study on 367 patients. Urol Int 1999;62:69-75.

6 Hessan H, Strauss M, Sharkey FE: Urogenital tract carcinoma metastatic to the head and neck. Laryngoscope 1986;96:1352-1356.

7 Matsui Y, Nishiyama H, Watanabe J, Teramukai S, Ono Y, Ohshima S, Fujimoto $\mathrm{K}$, Hirao Y, Fukushima M, Ogawa O: The current status of perioperative chemotherapy for invasive bladder: a multiinstitutional retrospective study in Japan. Int J Clin Oncol 2005;10:133-138.

8 Chester JD, Hall GD, Forster M, Protheroe AS: Systemic chemotherapy for patients with bladder cancer - current controversies and future directions. Cancer Treat Rev 2004;30:343-358

9 Lorusso V, Silvestris N: Systemic chemotherapy for patients with advanced and metastatic bladder cancer: current status and future directions. Ann Oncol 2005;16(suppl 4):iv85-iv89.

10 Hemal AK, Khaitan A, Dinda AK, Gupta NP, Seth A, Dogra PN, Nabia G: Prognostic significance of $\mathrm{p} 53$ nuclear overexpression in patients of muscle invasive urinary bladder carcinoma treated with cystectomy. Urol Int 2003;70:4246.

11 Uygur MC, Yaman I, Kutlay L, Altug U, Erol D: The relation between p53 over expression and lymph node metastases in clinical stage $\mathrm{t} 2$ and $\mathrm{t} 3 \mathrm{a}$ transitional cell bladder cancer. J Exp Clin Cancer Res 1999;18:391-395.

12 Vazina A, Dugi D, Shariat SF, Evans J, Link R, Lerner SP: Stage specific lymph node metastasis mapping in radical cystectomy specimens. J Urol 2004;171:18301834 . 